\title{
Universal School Meals in the US: What Can We Learn from the Community Eligibility Provision?
}

\author{
Tatiana Andreyeva*(D) and Xiaohan Sun
}

Citation: Andreyeva, T.; Sun, X. Universal School Meals in the US: What Can We Learn from the Community Eligibility Provision? Nutrients 2021, 13, 2634. https:// doi.org/10.3390/nu13082634

Academic Editor: Antoni Sureda

Received: 1 July 2021

Accepted: 27 July 2021

Published: 30 July 2021

Publisher's Note: MDPI stays neutral with regard to jurisdictional claims in published maps and institutional affiliations.

Copyright: (c) 2021 by the authors. Licensee MDPI, Basel, Switzerland. This article is an open access article distributed under the terms and conditions of the Creative Commons Attribution (CC BY) license (https:// creativecommons.org/licenses/by/ $4.0 /)$.
Rudd Center for Food Policy and Obesity, Department of Agricultural and Resource Economics, University of Connecticut, 1 Constitution Plaza, Hartford, CT 06103, USA; xiaohan.sun@uconn.edu

* Correspondence: tatiana.andreyeva@uconn.edu; Tel.: +1-860-380-1014

\begin{abstract}
Changes in school meal programs can affect well-being of millions of American children. Since 2014, high-poverty schools and districts nationwide had an option to provide universal free meals (UFM) through the Community Eligibility Provision (CEP). The COVID-19 pandemic expanded UFM to all schools in 2020-2022. Using nationally representative data from the Early Childhood Longitudinal Study: Kindergarten Class of 2010-2011, we measured CEP effects on school meal participation, attendance, academic achievement, children's body weight, and household food security. To provide plausibly causal estimates, we leveraged the exogenous variation in the timing of CEP implementation across states and estimated a difference-in-difference model with child random effects, school and year fixed effects. On average, CEP participation increased the probability of children's eating free school lunch by $9.3 \%$ and daily school attendance by 0.24 percentage points $(p<0.01)$. We find no evidence that, overall, CEP affected body weight, test scores and household food security among elementary schoolchildren. However, CEP benefited children in low-income families by decreasing the probability of being overweight by $3.1 \%(p<0.05)$ and improving reading scores of Hispanic children by 0.055 standard deviations. UFM expansion can particularly benefit at-risk children and help improve equity in educational and health outcomes.
\end{abstract}

Keywords: child nutrition; universal school meals; schools

\section{Introduction}

On a typical school day, almost 30 million students eat lunch served through the National School Lunch Program (NSLP) and 14.8 million students have breakfast via the School Breakfast Program [1]. Most of these meals - 85\% for breakfast, 74\% for lunch [1] are served free or at reduced prices, targeting children at greater risk for food insecurity and poor diet. All school meals must meet USDA nutrition standards [2] that ensure all children's access to nutritious foods. Participation in the NSLP has been linked to improvements in children's dietary intake and health, with most significant gains observed among nutritionally-disadvantaged low-income children [3-5]. As school meals are almost universal (99\% of US public schools and $83 \%$ of private schools participate in NSLP [6]), any changes in school nutrition have potential to affect the diets of millions of American children. Increasing evidence suggests that the quality of diet can impact academic achievement, school attendance, long-life income, and health $[7,8]$, so changes in school nutrition have implications far beyond dietary outcomes.

In 2010, the Healthy, Hunger-Free Kids Act (HHFKA) initiated a number of changes in the school meal programs, including the establishment of the Community Eligibility Provision (CEP) that was intended to increase school meal participation and improve food security among children in high-poverty communities. Despite widespread access to the NSLP, many eligible low-income students (from 16\% in elementary schools to $36 \%$ in high schools) did not participate due to common stigmatization, access to competitive foods and other barriers $[9,10]$. CEP allowed the provision of universal free meals (UFM) in highpoverty schools if $\geq 40$ percent of students in the prior year could be directly certified for 
free meals (i.e., students identified as participating in other food assistance programs, such as the Supplemental Food Assistance Program). CEP eliminated the household application process and streamlined meal counts and claiming procedures, which was expected to reduce the administrative burden and related costs to local school districts [11,12]. On a broader scale, the idea behind CEP was that better nutrition through CEP for children previously not benefiting from school meals could improve child's wellbeing and reduce socio-economic disparities in education and health.

Important to the identification strategy in this study, CEP was implemented gradually over four years, with first school districts becoming eligible for CEP in school year (SY) 2011-2012 in three pilot states (IL, KY, MI), followed by districts in four states (DC, NY, $\mathrm{OH}, \mathrm{WV}$ ) next year, and additional four states (GA, FL, MA, MD) in SY 2013-2014. All remaining states became eligible in SY 2014-2015 [12]. In its second year of national CEP availability, more than 18,000 high-poverty schools, or half of eligible schools, chose to participate in CEP [13]. School districts of a bigger size, located in the Southeast, urban districts, and with at least one school receiving full reimbursements were more likely to adopt the CEP [14]. As of 2020, 33,171 schools across the nation, or $68 \%$ of eligible schools, adopted CEP [15], which significantly expanded access to free nutritious school meals.

Recent evaluations, most from specific states, have found that the adoption of CEP has improved school meal participation [16-21], attendance [18,22-24], academic achievement $[18,19,23,24]$, and school food service finances $[25,26]$. At the same time, CEP was shown to reduce out-of-school suspension and expulsion rates $[23,27]$. Research on obesity implications has produced mixed results, varying from a reduction in body mass index (BMI) across grades [28], increased BMI percentile [29], and reduced BMI and obesity among select student groups only $[18,26,29]$. It is yet unknown whether CEP implementation has translated into measurable nutrition and health gains for children nationwide, and how these gains were distributed across population sub-groups. Potential co-benefits of improved school meal participation need further documentation, including effects on household food security, academic achievement, family and school finances.

This study provides a comprehensive, nationwide assessment of the multiple impacts that CEP has brought to low-income communities in its early years (2011-2016), including effects on school meal participation, attendance, academic achievement, children's body weight, and household food security. Drawing on the exogenous variation in the timing of CEP adoption across states, we used a quasi-experimental approach of comparing the temporal change in outcomes between the treatment and control groups (i.e., a differencein-difference model) to provide plausibly causal estimates of the CEP effects in a national longitudinal sample of elementary schoolchildren. To understand how vulnerable groups were affected across the spectrum of outcomes, the study included multiple sub-group analyses.

\section{Materials and Methods}

\subsection{Data}

We used a nationally representative panel of U.S. children from the Early Childhood Longitudinal Study, Kindergarten Class of 2010-2011 (ECLS-K:2011), which selected children from public and private schools attending full- or part-day kindergarten in 2010-2011. ECLS-K:2011 focused on children's early school experiences, beginning with kindergarten entry and through the fifth grade, with data collection in the fall and spring of kindergarten, first grade and second grade, and the spring of third, fourth and fifth grades. The study included parent, teacher, school administrator, and child-level data on children's cognitive and social development, home environment, test scores, child's health, body weight and height, and behavior [30].

We used child assessment, parent-, teacher- and school administrator-reported data from all six spring waves. To enable linkages between the school's location and child-level outcomes, we used a restricted version of the ECLS-K:2011 with geographic identifiers, which was provided by the National Center for Education Statistics at the US Department 
of Education [30]. The sample had children from 41 states for the period of 2011-2016, including 9 CEP pilot states (FL, GA, IL, MA, MD, MI, NY, OH and WV).

Data on school-level CEP eligibility and participation in all states in SY 2014-2015 and SY 2015-2016 were obtained from the Food Research and Action Center (FRAC) and the Center on Budget and Policy Priorities (CBPP) [31,32]. To define CEP eligibility and participation for pilot states during SY 2011-2014, we collected administrative data from State Departments of Education and another researcher studying CEP [19].

As the ECLS-K:2011 did not include school names and did not collect data on CEP, additional steps were necessary to enable a link between the ECLS-K:2011 with administrative data on school CEP eligibility and participation. School names were collected from external data sources, including the Common Core of Data (CCD) for public schools and the Private School Universe Survey (PSS) for private schools [33,34]. The ECLS-K:2011 included CCD and PSS identifiers, which were used to locate each school by name and location to enable a merge with administrative data on CEP. The merge used a fuzzy matching function in STATA based on school, school district, and state names. All matching results were manually checked.

\subsection{Sample Selection}

The study population was elementary schoolchildren (K through 5 th grade) that attended kindergarten in 2010-2011. As CEP eligible schools and/or school districts were not required to participate in CEP, participation decisions were choices that could be correlated with unobservable factors also affecting school and child-level outcomes. Reverse causality is another threat in that a school/district's performance on certain outcomes could affect its decision to participate in CEP. To demonstrate the point on potential selection bias into CEP, Table 1 demonstrates significant differences in the observable mean characteristics of schools that chose to participate in CEP and non-participating schools, including those that were eligible but selected not to participate. To account for potential selection bias and consistent with previous economic research $[18,19]$, the analytic sample in this study was limited to children attending schools that participated in CEP at any point in our data in 2011-2016, excluding children in CEP ineligible (i.e., higher income) schools/districts and CEP eligible schools/districts that did not participate in CEP within two years of its nationwide implementation.

\subsection{Measures}

The study included multiple outcomes of the CEP effects, including school meal participation, school attendance, academic achievement, child's body weight, and household food security. School meal participation was assessed based on two measures: (1) school administrators' reported percentage of children eligible for free or reduced-price lunchreferred below as free school meals, and (2) parental reports of their child's receiving free school lunch. Attendance was reported by school administrators as a percent of enrolled children attending school on an average day. Academic achievement included assessments of a student's proficiency in reading, math and science that were measured by direct child cognitive assessment scale scores using the Item Response Theory (IRT) procedures. The test performance metrics were transformed into z-scores normalized using grade-by-year means and variances of each subject. 
Table 1. Survey-adjusted School Characteristics by CEP Participation and Eligibility Status in the Analytic Sample from the Early Childhood Longitudinal Study, Kindergarten Class of 2010-2011 (ECLS-K:2011).

\begin{tabular}{|c|c|c|c|}
\hline School Characteristic & CEP Ineligible Schools & $\begin{array}{l}\text { CEP Eligible, but Not } \\
\text { Participating Schools }\end{array}$ & CEP Participating Schools \\
\hline & Mean or \% $(95 \% \mathrm{CI})$ & Mean or \% $(95 \% \mathrm{CI})$ & Mean or $\%(95 \% \mathrm{CI})$ \\
\hline $\begin{array}{l}\% \text { children eligible for } \\
\text { free/reduced-price lunch }\end{array}$ & $26.4(24.6,28.2)$ & $57.2(55.4,59.0)$ & $78.8(76.8,80.8)^{* * *}$ \\
\hline$\%$ of poverty in school district & $13.5(12.9,14.2)$ & $20.1(19.4,20.7)$ & $30.5(29.4,31.5) * * *$ \\
\hline Title I school & $51.0(46.7,55.2)$ & $80.1(77.2,83.1)$ & $94.5(92.3,96.7)^{* * *}$ \\
\hline Public school & $76.5(73.1,79.8)$ & $91.7(89.7,93.7)$ & $98.4(97.1,99.7) * * *$ \\
\hline$\%$ of Hispanic children & $19.5(17.6,21.3)$ & $29.5(27.5,31.5)$ & $26.8(23.9,29.6)$ \\
\hline$\%$ of black non-Hispanic children & $6.5(5.5,7.4)$ & $13.1(11.9,14.4)$ & $30.8(28.0,33.5)^{* * *}$ \\
\hline$\%$ of white non-Hispanic children & $59.6(57.1,62.1)$ & $48.2(46.0,50.4)$ & $26.6(23.3,30.0) * * *$ \\
\hline Suburban town & $56.7(53.0,60.4)$ & $55.5(52.1,58.9)$ & $30.2(25.7,34.7) * * *$ \\
\hline Rural area & $19.1(15.9,22.3)$ & $23.3(20.2,26.5)$ & $10.4(7.3,13.5)^{* * *}$ \\
\hline Enrollment $<300$ students & $22.1(17.8,26.3)$ & $18.0(14.3,21.7)$ & $16.8(12.0,21.6)$ \\
\hline Enrollment $>500$ students & $48.6(43.9,53.2)$ & $51.9(47.5,56.2)$ & $48.2(42.2,54.3)$ \\
\hline Number of schools & 1100 & 1400 & 700 \\
\hline
\end{tabular}

CEP: Community Eligibility Provision; 95\% CI: 95\% confidence intervals. SOURCE: U.S. Department of Education, National Center for Education Statistics, Early Childhood Longitudinal Study, Kindergarten Class of 2010-2011 (ECLS-K:2011), 2011-2016. According to the regulations for restricted-use data produced by the Institute of Education Sciences Data Security Office, all sample sizes are rounded to the nearest 50. School level descriptive statistics were adjusted using a full sample school weight. ${ }^{* * *} p<0.01$.

The child's height and weight, which were measured by the ECLS-K:2011 study's personnel, were used to construct age- and gender-specific BMI percentiles and z-scores. Indicators for child overweight (BMI percentile: 85.0-94.99) and overweight/obesity (BMI percentile: 85.0 and above) were used to assess children's BMI status. Finally, household food security was assessed based on parental responses to the 10-item version of the USDA's adult food security measure. Three binary outcomes were created, including an indicator of a food secure household ( $<3$ affirmative responses to 10 food security items), one for low food security (3-5 affirmative responses), and one for very low food security ( $\geq 6$ affirmative responses). Adult food security was used as a measure of household food security given few reports of food disruptions among children and a very small sample size for child food security.

The main independent variable was an indicator for whether a child attended a CEPparticipating school during the academic year. Socio-demographic controls at the child and household-level included the child's gender, race/ethnicity, household income below the $200 \%$ federal poverty level, primary language at home other than English, and mother's education. Child's birth weight was used as a covariate in BMI models only. At the school level, percentage of poverty in a school district and the duration of CEP participation were added as covariates.

\subsection{Estimation Model}

The identification strategy was based on the variation in the timing of state CEP eligibility, which was set independently of school districts by the US Department of Agriculture [12]. The different timing of CEP adoption allowed the use of a difference-in-difference model to identify causality. Assuming random nature of the USDA's selection of pilot states and that early implementation upon eligibility had no more benefits than later im- 
plementation, the difference-in-difference model can measure the causal effect of CEP by comparing early to late CEP-adopting schools. The model was specified as:

$$
Y_{j t}=\beta_{0}+\beta_{1} C E P_{j t}+\beta_{2} X_{j t}+\mu_{s}+\gamma_{t}+\pi_{j}+\varepsilon_{j t},
$$

where $Y_{j t}$ is the outcome for child $j$ in year $t, C E P_{j t}$ is a dichotomous measure of whether a child's school participated in CEP in year $t, X_{j t}$ is a vector of child, family, and schoollevel covariates for child $j$ in year $t, \mu_{s}$ is a school fixed effect for time-invariant school characteristics, $\gamma_{t}$ is a year fixed effect, $\pi_{j}$ represents a child random effect to control for time-invariant heterogeneity at the child level, and $\varepsilon_{j t}$ is the error term. $\beta_{1}$ captures a causal estimate of the CEP effects under the assumption that the CEP adoption time is exogenous. This means that both the school's adoption time and the adoption time within students was random. A Hausman test was conducted to test the validity of the child random-effects model by comparing the child random-effects and fixed-effects models, with results favoring the random-effects model. Robust standard errors were clustered at the child level. All models were estimated using a linear probability model based on the distribution of residuals that were almost equally and randomly distributed centering around zero for all outcomes.

As CEP launched as a pilot in three states in school year (SY) 2011-2012, CE $P_{j t}$ was set to 0 for all children in school year 2010-2011 (kindergarten). The duration of the pre- and post-CEP period varied depending on the child's state and the timing of CEP adoption. Children residing in pilot states that implemented CEP earlier than the rest of the country had a longer exposure to CEP, beginning in the 1st to 5th grade. Children residing in the states that adopted CEP in SY 2014-2015 had up to two years of the program exposure, in 4th and 5th grades only. We also tested the difference between CEP early adopters (adoption before 2014-2015) and late adopters (2015-2016).

The key assumption of the difference-in-difference model is the parallel trends, which implies that the trends of change in the control group would be the same as the trends of change in the treatment group in the absence of the policy [35]. For example, if outcomes in the treatment group were improving faster than in the control group before the policy change, the difference-in-difference model would overestimate the policy effect. This study tested the parallel trends assumption using an event study framework to account for the variation in the timing of the policy change (i.e., CEP eligibility), which is consistent with prior economic research on CEP $[18,19]$. Specifically, the model in equation (1) was re-estimated by including a set of indicators to capture the years before and after the CEP introduction. The leads and lags of the CEP indicators included one year, two years and three or more years prior to the CEP adoption, and similar periods following the policy change. The results in Supplementary Materials Figures S1-S3 for the full sample show that the coefficients in the years prior to the CEP adoption were not statistically different from zero, supporting the parallel trends assumption.

\section{Sensitivity Analyses and Robustness Checks}

We conducted a variety of tests to check robustness of our results. One sensitivity analysis tested the hypothesis that children could switch schools to get access to UFM, which would have violated our model's assumption that the adoption time within students was exogenous and unrelated to unobserved characteristics of the children. To test this hypothesis, we limited the sample to students whose change in the CEP status was due to their school's change rather than students switching schools. Specifically, $42 \%$ of children in our analytic sample changed their CEP participation status by changing schools-due to moving, a school switch, or the school district design of separate K-2 and 3-5 schools. At the same time, $58 \%$ students had the change because their school implemented CEP.

Additional sensitivity analyses included estimation of generalized linear models, alternative outcomes (e.g., BMI percentile instead of BMI z-score), estimating a Beta regression for attendance outcomes, using two datapoints DID model by grade, comparing regression with or without panel weights, and school covariates instead of school fixed effects (which 
did not pass the Hausman test). We further tested sensitivity of our results by re-estimating model (1) using child fixed effects instead of child random effects. Results for the child fixed effects models were similar with the main results presented. Additional sensitivity analysis included the exclusion of children with extreme values on BMI z-scores.

To assess heterogeneity in the effects of CEP participation across children, the study included several subgroup analyses: i.e., by household income, child's race/ethnicity, prior receipt of free/reduced price school meals, and language at home other than English.

\section{Results}

The analytic sample of children in CEP-participating schools included around 2500 children (all sample size numbers were rounded to the nearest 50 per the ECLS-K:2011 disclosure requirements). Table 2 presents descriptive statistics for the study outcomes and covariates for children attending elementary schools that participated in CEP at any point during 2011-2016 (our analytic sample) and children from schools not on CEP during this period. Results show significant disparities in the characteristics of children based on their school CEP participation status, including higher rates of economically-disadvantaged children, racial/ethnic minorities, children speaking non-English at home, and children attending high-poverty, urban schools in the CEP group. Further, children in elementary schools that adopted CEP by 2015-2016 were more likely to have lower academic achievement, participate in school meal programs, and have higher rates of obesity and household food insecurity than their peers in non-participating schools. These large differences highlight the importance of restricting the analytic sample in this CEP study to children in CEP schools only.

Table 2. Child Characteristics by CEP Participation Status from the Early Childhood Longitudinal Study, Kindergarten Class of 2010-2011 (ECLS-K:2011).

\begin{tabular}{|c|c|c|}
\hline Child Characteristic & Attending Non-CEP School & Attending CEP School \\
\hline & Mean or $\%(95 \% \mathrm{CI})$ & Mean or $\%(95 \% \mathrm{CI})$ \\
\hline White non-Hispanic & $51.4(51.1,51.8)$ & $24.5(23.8,25.2) * * *$ \\
\hline Black non-Hispanic & $9.3(9.1,9.5)$ & $23.4(22.7,24.0) * * *$ \\
\hline Hispanic & $24.5(24.2,24.9)$ & $38.2(37.4,39.0) * * *$ \\
\hline Asian & $8.8(8.6,9.0)$ & $9.0(8.6,9.5)$ \\
\hline Other race & $5.9(5.7,6.1)$ & $4.9(4.6,5.3)^{* * *}$ \\
\hline Male & $51.2(50.8,51.5)$ & $52.0(51.2,52.8) *$ \\
\hline Primary language at home other than English & $20.1(19.8,20.4)$ & $33.0(32.2,33.8)^{* * *}$ \\
\hline Child with disability & $32.0(31.6,32.3)$ & $32.8(32.0,33.6) *$ \\
\hline Mother has less than high school education & $11.2(10.9,11.5)$ & $23.7(22.8,24.5)^{* * *}$ \\
\hline $\begin{array}{c}\text { Household income below } 200 \% \text { poverty } \\
\text { threshold }\end{array}$ & $33.5(33.1,33.8)$ & $61.5(60.7,62.3)^{* * *}$ \\
\hline$\%$ district poverty in child's school & $17.9(17.8,18.0)$ & $29.2(29.0,29.4) * * *$ \\
\hline$\%$ of Hispanic students in child's school & $21.8(21.6,22.0)$ & $34.7(34.1,35.3) * * *$ \\
\hline$\%$ of Asian students in child's school & $4.3(4.3,4.4)$ & $3.8(3.7,3.9)^{* * *}$ \\
\hline $\begin{array}{l}\% \text { of black non-Hispanic students in child's } \\
\text { school }\end{array}$ & $10.7(10.6,10.8)$ & $23.1(22.7,23.6)^{* * *}$ \\
\hline $\begin{array}{l}\% \text { of white non-Hispanic students in child's } \\
\text { school }\end{array}$ & $56.2(55.9,56.4)$ & $28.6(28.1,29.1) * * *$ \\
\hline Child's school receives funds from Title I & $71.4(71.0,71.8)$ & $94.3(94.0,94.7) * * *$ \\
\hline $\begin{array}{l}\% \text { of children in special education with an } \\
\text { Individualized Education Program (IEP) }\end{array}$ & $7.8(7.8,7.9)$ & $8.8(8.7,8.9)^{* * *}$ \\
\hline Attending public school & $88.4(88.2,88.6)$ & $98.3(98.1,98.5)^{* * *}$ \\
\hline Attending suburban school & $56.0(55.6,56.4)$ & $34.4(33.6,35.2) * * *$ \\
\hline Attending rural school & $26.3(26.0,26.6)$ & $13.4(12.8,13.9)^{* * *}$ \\
\hline Attending school with enrollment less than 300 & $16.9(16.6,17.2)$ & $13.1(12.5,13.7)^{* * *}$ \\
\hline Attending school with enrollment more than 500 & $54.9(54.5,55.3)$ & $53.8(52.9,54.7) * *$ \\
\hline
\end{tabular}


Table 2. Cont.

\begin{tabular}{|c|c|c|}
\hline Child Characteristic & Attending Non-CEP School & Attending CEP School \\
\hline Reading proficiency z-score & $0.066(0.059,0.074)$ & $-0.318(-0.334,-0.301)^{* * *}$ \\
\hline Math proficiency z-score & $0.069(0.061,0.076)$ & $-0.329(-0.346,-0.313)^{* * *}$ \\
\hline Science proficiency z-score & $0.075(0.068,0.082)$ & $-0.367(-0.383,-0.350) * * *$ \\
\hline $\begin{array}{c}\% \text { of students attending school daily in current } \\
\text { school year }\end{array}$ & $95.5(95.5,95.5)$ & $95.0(95.0,95.1)^{* * *}$ \\
\hline $\begin{array}{l}\% \text { of children reported by school administrators } \\
\text { eligible for free or reduced-price lunch }\end{array}$ & $43.4(43.2,43.6)$ & $75.0(74.5,75.4)^{* * *}$ \\
\hline $\begin{array}{l}\% \text { of parents reporting child's receipt of free or } \\
\text { reduced-price school lunch }\end{array}$ & $44.2(43.7,44.7)$ & $80.5(79.6,81.3)^{* * *}$ \\
\hline BMI z-score & $0.467(0.456,0.477)$ & $0.606(0.579,0.633) * * *$ \\
\hline$\%$ overweight & $15.7(15.4,15.9)$ & $17.0(16.4,17.7)^{* * *}$ \\
\hline$\%$ overweight/obese & $32.0(31.7,32.4)$ & $39.3(38.5,40.1)^{* * *}$ \\
\hline Food secure household & $91.9(91.7,92.2)$ & $87.3(86.6,88.0)^{* * *}$ \\
\hline Household with low food security & $5.6(5.4,5.8)$ & $9.2(8.6,9.9)^{* * *}$ \\
\hline Household with very low food security & $2.5(2.3,2.6)$ & $3.5(3.1,3.9) * * *$ \\
\hline Number of children & 15,300 & 2500 \\
\hline
\end{tabular}

CEP: Community Eligibility Provision; 95\% CI: 95\% confidence intervals; BMI: body mass index. SOURCE: U.S. Department of Education, National Center for Education Statistics, Early Childhood Longitudinal Study, Kindergarten Class of 2010-2011 (ECLS-K:2011), $2011-2016$. According to the regulations for restricted-use data produced by the Institute of Education Sciences Data Security Office, all sample sizes are rounded to the nearest $50 .{ }^{* *} p<0.01^{* *} p<0.05^{*} p<0.1$.

Results from the difference-in-difference model of the CEP effects for U.S. elementary schoolchildren in 2011-2016 are presented in Table 3. The full sample results are shown in Column 1, suggesting a statistically significant increase in school meal participation and receipt of free school lunch, as well as improved school attendance, but no measurable changes in other outcomes. Specifically, CEP increased access to free school lunch by 2.4 percentage points $(p<0.01)$. Based on parental reports, CEP increased the probability of children getting free school lunch by $9.3 \%(p<0.01)$. Furthermore, CEP also improved school attendance by increasing the percent of students attending daily by 0.24 percentage points $(p<0.01)$. Models for academic achievement outcomes did not pass the parallel trend assumption and are therefore not reported, but no significant results were identified in the full analytic sample. CEP was found to have no effect on body weight outcomes and household food security among elementary schoolchildren in 2011-2016.

Sub-group analyses revealed important heterogeneity in the CEP effects across children of diverse backgrounds, with several results indicating a larger and more significant effect on children from less-advantaged families. For example, children from low-income families (Column 2) that could be affected by UFM if not previously participating in the free school meal programs, had a reduction in the probability of being overweight by $3.1 \%(p<0.05)$. This result was in addition to improved school meal participation and school attendance also seen in the full sample, with estimated effects of the equivalent magnitude. The sub-sample of Hispanic children (Column 3) showed a marginally significant CEP-attributable increase in reading scores, on average by 0.055 standard deviations $(p<0.1)$. Math and science scores, however, were not affected, while all models of academic achievement for Hispanic children passed the parallel trend test. Furthermore, among children not receiving free/reduced price lunch before CEP, we saw a particularly large increase in the probability of a child's receiving free school meals, by $40.7 \%(p<0.01)$, but other outcomes were not significant. Finally, the only significant result for children whose primary language at home was not English was increased school attendance, by 0.436 percentage points $(p<0.05)$. For all sub-groups, there was no evidence that CEP affected household food security in a significant way. Our sensitivity analyses showed results that were consistent with the results of the full sample or the main specification model. 
Table 3. Estimated CEP Effects on Elementary Schoolchildren, 2011-2016.

\begin{tabular}{|c|c|c|c|c|c|}
\hline \multirow[b]{2}{*}{ Outcome } & \multirow[b]{2}{*}{$\begin{array}{c}\text { Full Sample } \\
\beta(95 \% \text { CI }) \\
\text { N }\end{array}$} & \multicolumn{4}{|c|}{ Sub-Groups of Elementary Schoolchildren } \\
\hline & & $\begin{array}{c}\text { Low-Income } \\
\beta(95 \% \mathrm{CI}) \\
\mathbf{N}\end{array}$ & $\begin{array}{c}\text { Hispanic } \\
\beta(95 \% \text { CI }) \\
\text { N }\end{array}$ & $\begin{array}{c}\text { No Receipt of Free/Reduced Price School } \\
\text { Meals before CEP } \\
\beta(95 \% \mathrm{CI}) \\
\text { N }\end{array}$ & $\begin{array}{c}\text { Primary Language at Home Other } \\
\text { than English } \\
\beta(95 \% \mathrm{CI}) \\
\mathrm{N}\end{array}$ \\
\hline$\%$ of schoolchildren eligible for free lunch & $\begin{array}{c}2.396 * * *(1.493,3.299) \\
12,750\end{array}$ & $\begin{array}{c}1.980 * * *(0.894,3.066) \\
7850\end{array}$ & N.R. & $\begin{array}{c}1.288 \\
(-0.609,3.186) \\
2950\end{array}$ & $\begin{array}{c}0.827 \\
(-0.558,2.211) \\
4400\end{array}$ \\
\hline Receipt of free lunch in parental report & $\begin{array}{c}0.093^{* * *}(0.065,0.120) \\
7750\end{array}$ & $\begin{array}{c}-0.007 \\
(-0.031,0.016) \\
4700\end{array}$ & $\begin{array}{c}\mathbf{0 . 0 4 1}{ }^{* *}(0.003,0.078) \\
3100\end{array}$ & $\begin{array}{c}\mathbf{0 . 4 0 7} \mathbf{7}^{* * *}(0.347,0.468) \\
1550\end{array}$ & $\begin{array}{c}-0.014 \\
(-0.050,0.023) \\
2700\end{array}$ \\
\hline$\%$ students attending school & $\begin{array}{c}\mathbf{0 . 2 4 4} \mathbf{4}^{* * *}(0.061,0.426) \\
10,350\end{array}$ & $\begin{array}{c}0.301^{* *}(0.038,0.565) \\
6300\end{array}$ & N.R. & $\begin{array}{c}0.083 \\
(-0.195,0.361) \\
2400\end{array}$ & $\begin{array}{c}0.436^{* *}(0.077,0.795) \\
3450\end{array}$ \\
\hline Reading proficiency z-score & N.R. & N.R. & $\begin{array}{c}\mathbf{0 . 0 5 5} \text { * } \\
(-0.008,0.119) \\
5050 \\
0.003\end{array}$ & $\begin{array}{c}0.009 \\
(-0.056,0.073) \\
2950\end{array}$ & $\begin{array}{c}0.053(-0.011,0.018) \\
4300\end{array}$ \\
\hline Math proficiency z-score & N.R. & N.R. & $\begin{array}{c}(-0.050,0.056) \\
5050\end{array}$ & N.R. & N.R. \\
\hline Science proficiency z-score & N.R. & N.R. & $\begin{array}{c}-0.015 \\
(-0.080,0.051) \\
4950\end{array}$ & $\begin{array}{c}-0.019 \\
(-0.092,0.054) \\
2950\end{array}$ & $\begin{array}{c}-0.053(-0.119,0.013) \\
4200\end{array}$ \\
\hline BMI z-score & $\begin{array}{c}0.001 \\
(-0.116,0.117) \\
12,050\end{array}$ & $\begin{array}{c}0.065 \\
(-0.048,0.179) \\
7400\end{array}$ & $\begin{array}{c}-0.033 \\
(-0.151,0.085) \\
4800\end{array}$ & $\begin{array}{c}-0.123 \\
(-0.437,0.190) \\
2800\end{array}$ & $\begin{array}{c}0.012 \\
(-0.110,0.133) \\
4100\end{array}$ \\
\hline & $\begin{array}{l}12,000 \\
-0.014\end{array}$ & $\begin{array}{r}7400 \\
-0.031 * *\end{array}$ & $\begin{array}{c}4800 \\
-0.024\end{array}$ & $\begin{array}{l}2800 \\
0.003\end{array}$ & $\begin{array}{c}4100 \\
-0.027\end{array}$ \\
\hline Overweight & $(-0.037,0.009)$ & $(-0.061,0.000)$ & $(-0.063,0.016)$ & $(-0.037,0.043)$ & $(-0.067,0.012)$ \\
\hline & $\begin{array}{c}12,050 \\
0\end{array}$ & $\begin{array}{c}7400 \\
-0.008\end{array}$ & $\begin{array}{l}4800 \\
0.008\end{array}$ & $\begin{array}{l}2800 \\
0.012\end{array}$ & $\begin{array}{l}4100 \\
0.002\end{array}$ \\
\hline Obesity/overweight & $(-0.020,0.020)$ & $(-0.035,0.018)$ & $(-0.027,0.042)$ & $(-0.022,0.045)$ & $(-0.034,0.037)$ \\
\hline & 12,050 & 7400 & 4800 & 2800 & 4100 \\
\hline Food secure household & $\begin{array}{c}-0.013 \\
(-0.035,0.009) 8100\end{array}$ & $\begin{array}{c}-0.022 \\
(-0.058,0.014) 4700\end{array}$ & $\begin{array}{c}-0.009 \\
(-0.052,0.034) 3150\end{array}$ & $\begin{array}{c}-0.012 \\
(-0.035,0.011) 1950\end{array}$ & $\begin{array}{c}0.009 \\
(-0.035,0.053) 2750\end{array}$ \\
\hline Household with low food security & $\begin{array}{c}0.011 \\
(-0.008,0.031) 8100\end{array}$ & $\begin{array}{c}0.022 \\
(-0.010,0.054) 4700\end{array}$ & $\begin{array}{c}0.01 \\
(-0.031,0.051) 3150\end{array}$ & $\begin{array}{c}0 \\
(-0.016,0.016) 1950\end{array}$ & $\begin{array}{c}-0.002 \\
(-0.042,0.037) 2750\end{array}$ \\
\hline Household with very low food security & $\begin{array}{c}0.001 \\
(-0.013,0.014) 8100\end{array}$ & $\begin{array}{c}-0.002 \\
(-0.024,0.021) 4700\end{array}$ & $\begin{array}{c}-0.003 \\
(-0.024,0.018) 3150\end{array}$ & N.R. & $\begin{array}{c}-0.008 \\
(-0.033,0.018) 2750\end{array}$ \\
\hline
\end{tabular}

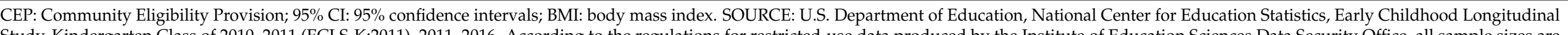

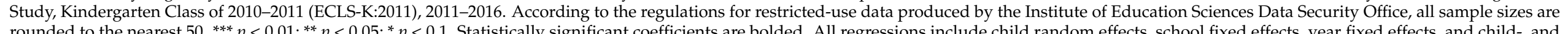

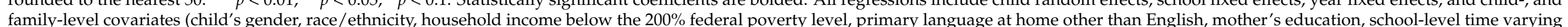
covariates (school district \% of poverty, duration of CEP participation). BMI-based models also include child's birth weight. N reports child-year observations. 


\section{Discussion}

This study finds that the adoption of CEP and UFM in the early years of the program's life has increased school meal participation and students' receipt of free school meals, improved school attendance, and had additional academic and health benefits for several sub-groups of at-risk children. Hispanic children were shown to particularly gain from CEP by having higher reading scores, while children from low-income families had a lower risk of being overweight with the adoption of CEP in their schools. We find no evidence that CEP affected household food security. Results are robust across multiple model specifications in our national sample of elementary schoolchildren in 2011-2016.

The findings of improved participation in school meals and greater use of free meals are consistent with data from prior studies, including two recent systematic reviews on the effects of CEP and UFM [36,37]. The magnitude of results in our national sample is, however, more modest, potentially due to our study design or the sample of younger elementary schoolchildren. Our research and prior studies confirm that CEP achieves its primary goal of increasing school meal participation and expanding reach for the School Breakfast Program and the National School Lunch Program [17-21,23,36,37]. We find evidence for improvements in school meal participation based on data from two independent sources, including school administrators and parents, which makes the findings more reliable. It is encouraging that the improvements seen in the school meal reach are particularly large for children who did not receive free/reduced-price school meals prior to the CEP adoption in their schools. It is possible these children were eligible, but did not participate due to stigma, lack of knowledge or administrative burdens [10,38]. CEP has removed these barriers for children and their families.

The observed improvement in school attendance is modest at 0.24 percentage points in the percent of children attending school, which fits mixed results on this outcome in the literature. Results vary from lower absences among elementary schoolchildren, but not middle-schoolers [24], to reduced poor attendance only among economically disadvantaged children in the second (but not first) year of the CEP implementation [22], and increased absences across grades [23]. School absenteeism is an important predictor of student achievement, high school and college graduation rates, adult income, and health $[39,40]$. Even modest improvements in attendance with CEP render important supports to the program's wider impacts outside of the direct effect on school meal participation. Future studies should continue assessments of the CEP effects on attendance and related long-term outcomes.

Our results on academic achievement are distinct from previous state-specific studies. It is possible that high heterogeneity in our sample of 41 states can explain the model's failure to confirm the parallel trend assumption for test scores, except for results among Hispanic children that are likely to be residing more narrowly in the Western and Southwestern states. Our sample size was too small to conduct state- or region-specific analyses. We tried an alternative model using school covariates and state covariates for region and political affiliation instead of school fixed effects, the results were very similar to our preferred model. It is important, however, that reading scores of Hispanic children were shown to increase with CEP participation even in the short term. The observed increase of a 0.055 standard deviation in the grade-adjusted reading z-scores is similar to the findings from other studies, including a 0.059 standard deviation increase for English Language Arts and 0.083 for math among non-poor students in NYC [18] and a 0.05 standard deviation increase in math in a national study [19]. Longer-term studies might be able to capture additional effects that improved access to nutritious school meals could bring to academic outcomes.

Finally, our study did not identify significant changes in household food security after the CEP's adoption, which would have been a major accomplishment of the UFM expansion. Relatively few families in the ECLS-K:2011 sample reported major disturbances in having continuous access to food, especially among children, so our statistical power could be limited. It is possible that the use of adult food security as a measure of household 
food insecurity was not sensitive enough to capture spillovers from children's access to free school meals. There are no studies yet of the CEP effects on family finances [37] and future research should focus specifically on the effects of CEP expansion on food and nutrition security, including during and after the COVID-19 pandemic.

\section{Strengths and Limitations}

This study is based on a nationally representative longitudinal sample of children with objective measures of key outcomes, including academic achievement and BMI, and survey data on school meal participation, attendance and household food security. To our knowledge, this is the first study that combines such a wide variety of outcomes in the CEP impact analysis. The longitudinal nature of the ECLK:2011 panel with geographic identifiers in its restricted-use version enable the use of a difference-in-difference model to estimate plausibly causal estimates of the CEP effects on a national sample of elementary schoolchildren.

Along with its strengths, the study is subject to several important limitations. First, the study is limited to elementary schoolchildren who had the lowest non-participation rates among eligible students prior to CEP [9] and might benefit less from the CEP's adoption than middle- or high schoolchildren. Failure to support the parallel trend assumption for key outcomes is another concern. Conducting a national study with large heterogeneity across states could explain some of our challenges in estimating the CEP effects as well as more modest estimated effects for some findings. The sample size in several sub-group analyses was small, which might have affected the results. Future research should study the effects of CEP and UFM, especially during and after COVID-19, on household food security and child nutrition. Our study did not have data on dietary effects of impacts of CEP expansion, which could be positive [5] and should be directly investigated in future research. Finally, studies of the CEP effects in older children are needed.

\section{Conclusions}

This paper provides evidence that CEP participation in its early years increased school meal participation and attendance in elementary schools, without adverse effects on student academic achievement and body weight outcomes. Expanding access to UFM appears to particularly benefit at-risk children, including gains in reading scores for Hispanic children and reduced risk of being overweight among children from low-income families. The COVID-19 pandemic led to the UFM implementation across all schools, irrespective of student incomes [41], which could lead to broader adoption of CEP in the long term. Two states (CA and ME) have recently passed legislation to make UFM a permanent program [42,43]. Our work suggests that access to UFM, without disruptions of remote learning during the COVID-19 pandemic, will likely benefit children's nutrition security and academic achievement, particularly among children from economically-vulnerable families. Future research should further investigate how UFM expansion can improve diet and reduce health and education disparities among American children.

Supplementary Materials: The following are available online at https://www.mdpi.com/article/10 $.3390 /$ nu13082634/s1, Figure S1: Event Study, Results: Daily school attendance (\%), Full Sample, Figure S2: Event Study, Results: School \% of eligible for free or reduced-price lunch, Full Sample, Figure S3: Event Study, Results: Child's receipt of complete school lunches for free or reduced price, Full Sample.

Author Contributions: Conceptualization, T.A.; methodology, T.A., X.S.; formal analysis, X.S.; data curation, X.S.; writing-original draft preparation, T.A.; writing-review and editing, T.A., X.S.; supervision, T.A.; funding acquisition, T.A. Both authors have read and agreed to the published version of the manuscript.

Funding: This paper was supported by Healthy Eating Research, a national program of the Robert Wood Johnson Foundation (grant \#76292). 
Institutional Review Board Statement: The study received approval of the Institutional Review Board (IRB) at the University of Connecticut to work with restricted-use ECLS-K data, protocol \#H19-048. All analyses were with secondary data.

Informed Consent Statement: Not applicable, secondary data analysis.

Data Availability Statement: The ECLS-K data is available through the National Center for Education Statistics at the US Department of Education.

Acknowledgments: The authors appreciate helpful feedback from Michael W. Long and gratefully acknowledge the advice of Timothy Moore and Joochul Lee of UConn's Statistical Consulting Services. The authors thank the Food Research and Action Center (FRAC), Krista Ruffini and state departments of education for sharing their CEP eligibility and participation data.

Conflicts of Interest: The authors declare no conflict of interest.

\section{References}

1. US Department of Agriculture, Food and Nutrition Service. Child Nutrition Tables—National Level Annual Summary Tables: FY 1969-2020. Available online: https:/ / www.fns.usda.gov/pd/child-nutrition-tables (accessed on 15 June 2021).

2. US Department of Agriculture, Food and Nutrition Service. National School Lunch Program and School Breakfast Program: Nutrition Standards for All Foods Sold in School as Required by the Healthy, Hunger-Free Kids Act of 2010. Final rule and interim final rule. Fed. Regist. 2016, 81, 50131-50151.

3. Micha, R.; Karageorgou, D.; Bakogianni, I.; Trichia, E.; Whitsel, L.P.; Story, M.; Peñalvo, J.L.; Mozaffarian, D. Effectiveness of school food environment policies on children's dietary behaviors: A systematic review and meta-analysis. PLoS ONE 2018, 13, e0194555. [CrossRef]

4. Gundersen, C.; Kreider, B.; Pepper, J. The impact of the national school lunch program on child health: A nonparametric bounds analysis. J. Econom. 2012, 166, 79-91. [CrossRef]

5. Smith, T.A. Do school food programs improve child dietary quality? Am. J. Agric. Econ. 2017, 99, 339-356. [CrossRef]

6. Institute of Medicine, Committee on Nutrition Standards for Foods in Schools. Nutrition Standards for Foods in Schools: Leading the Way toward Healthier Youth; The National Academies Press: Washington, DC, USA, 2007.

7. Michael, S.L.; Merlo, C.L.; Basch, C.E.; Wentzel, K.R.; Wechsler, H. Critical connections: Health and academics. J. Sch. Health 2015, 85, 740-758. [CrossRef] [PubMed]

8. Martin, A.; Booth, J.N.; Laird, Y.; Sproule, J.; Reilly, J.J.; Saunders, D.H. Physical activity, diet and other behavioural interventions for improving cognition and school achievement in children and adolescents with obesity or overweight. Cochrane Database Syst. Rev. 2018, 2, CD009728.

9. Fox, M.K.; Condon, E. School Nutrition Dietary Assessment Study IV, Summary of Findings; US Department of Agriculture, Food and Nutrition Service, Office of Research and Analysis: Alexandria, VA, USA, November 2012. Available online: https: //fns-prod.azureedge.net/sites/default/files/SNDA-IV_Findings_0.pdf (accessed on 26 July 2021).

10. Bhatia, R.; Jones, P.; Reicker, Z. Competitive foods, discrimination, and participation in the National School Lunch Program. Am. J. Public Health. 2011, 101, 1380-1386. [CrossRef] [PubMed]

11. US Department of Agriculture, Food and Nutrition Service. National School Lunch Program and School Breakfast Program: Eliminating Applications Through Community Eligibility as Required by the Healthy, Hunger-Free Kids Act of 2010. Final rule. Fed. Regist. 2016, 81, 50194-50210.

12. US Department of Agriculture, Food and Nutrition Service. Community Eligibility Provision: Planning and Implementation Guidance; Fall 2016 ed.; SP61-2016. Available online: https:/ / www.fns.usda.gov/cn/fall-2016-cep-planning-and-implementationguidance (accessed on 15 June 2021).

13. Segal, B.; Hewins, J.; Sanderson, M.; Nchako, C.; Neuberger, Z.; Cai, L.; Maurice, A. Community Eligibility Adoption Rises for the 2015-2016 School Year, Increasing Access to School Meals; Center for Budget and Policy Priorities, 2016; Volume 7, p. 13. Available online: https: / /www.cbpp.org/sites/default/files/atoms/files/4-7-16fa.pdf (accessed on 26 July 2021).

14. Rogus, S.; Guthrie, J.; Ralston, K. Characteristics of School Districts Offering Free School Meals to All Students Through the Community Eligibility Provision of the National School Lunch Program; ERR-255; US Department of Agriculture, Economic Research Service: Washington, DC, USA, August 2018. Available online: https://www.ers.usda.gov/webdocs/publications/89948/err-255.pdf?v= 0 (accessed on 26 July 2021).

15. Food Research and Action Center (FRAC). Community Eligibility: The Key to Hunger-Free Schools.School Year 2020-2021. June 2021. Available online: https:/ / frac.org/wp-content/uploads/CEP-Report-2021.pdf (accessed on 17 June 2021).

16. Logan, C.W.; Connor, P.; Harvill, E.L.; Harkness, J.; Nisar, H.; Checkoway, A.; Enver, A. Community Eligibility Provision Evaluation; Nutrition Assistance Program Report; US Department of Agriculture, Food and Nutrition Service, February 2014. Available online: https:/ / files.eric.ed.gov/fulltext/ED557961.pdf (accessed on 15 June 2021).

17. Pokorney, P.E.; Chandran, A.; Long, M.W. Impact of the Community Eligibility Provision on meal counts and participation in Pennsylvania and Maryland National School Lunch Programs. Public Health Nutr. 2019, 22, 3281-3287. [CrossRef] 
18. Schwartz, A.E.; Rothbart, M.W. Let them eat lunch: The impact of universal free meals on student performance. J. Policy Anal. Manag. 2020, 39, 376-410. [CrossRef]

19. Ruffini, K. Universal access to free school meals and student achievement: Evidence from the Community Eligibility Provision. J. Hum. Resour. 2021, 0518-9509R3. [CrossRef]

20. Turner, L.; Guthrie, J.F.; Ralston, K. Community eligibility provision and other provisions for universal free meals at school: Impact on student breakfast and lunch participation in California public schools. Transl. Behav. Med. 2019, 9, 931-941. [CrossRef] [PubMed]

21. Heflin, C.; Miller, D.P.; Community Eligibility and Child Well-Being. USDA RIDGE Project Summaries. 2016. Available online: https: / / data.ers.usda.gov /FANRP-ridge-project-summaries.aspx?type=2\&summaryId=277 (accessed on 15 June 2021 ).

22. Bartfeld, J.S.; Berger, L.; Men, F. Universal access to free school meals through the Community Eligibility Provision is associated with better attendance for low-income elementary school students in Wisconsin. J. Acad. Nutr. Diet. 2020, 120, 210-218. [CrossRef]

23. Kho, A. Three Essays on School Reform. Dissertation, Vanderbilt University, Nashville, TN, USA, August 2018. Available online: https:/ / etd.library.vanderbilt.edu/etd-07202018-130416 (accessed on 15 June 2021).

24. Gordanier, J.; Ozturk, O.D.; Williams, B.; Zhan, C. Free lunch for all! The effect of the Community Eligibility Provision on academic outcomes. Econ. Educ. Rev. 2020, 77, 101999. [CrossRef]

25. Long, M.W.; Marple, K.; Andreyeva, T. Universal free meals associated with lower meal costs while maintaining nutrition quality. Nutrients 2021, 13, 670. [CrossRef]

26. Rothbart, M.W.; Schwartz, A.E.; Gutierrez, E. Paying for Free Lunch: The Impact of CEP Universal Free Meals on Revenues, Spending, and Student Health. Center for Policy Research. 259. 2020. Available online: https://surface.syr.edu/cpr/259 (accessed on 20 March 2021).

27. Gordon, N.; Ruffini, K. Schoolwide free meals and student discipline: Effects of the Community Eligibility Provision. Educ. Financ. Policy 2019, 19, 1-50. [CrossRef]

28. Davis, W.; Musaddiq, T. Estimating the Effects of Universal Free School Meal Enrollment on Child Health: Evidence from the Community Eligibility Provision in Georgia Schools. February 2019. Available online: https://ssrn.com/abstract=3155354 (accessed on 15 June 2021).

29. Davis, G. Essays on the Economic Determinants of Health. Dissertation, Georgia State University, Atlanta, GA, USA, Summer. 2020. Available online: https:/ / scholarworks.gsu.edu/aysps_dissertations/17 (accessed on 15 June 2021).

30. National Center for Education Statistics, Institute of Education Sciences. Early Childhood Longitudinal Studies (ECLS) Program, Kindergarten Class of 2010-11 (ECLS-K:2011). Available online: https:/ /nces.ed.gov/ecls/kindergarten2011.asp (accessed on 15 June 2021).

31. Center on Budget and Policy Priorities (CBPP). Community Eligibility Provision 2014-15 Data; Provided by FRAC Per Request; Center on Budget and Policy Priorities: Washington, DC, USA, 25 March 2019.

32. Food Research and Action Center (FRAC); Center on Budget and Policy Priorities (CBPP). Community Eligibility Provision 2015-16 Data; Provided by FRAC Per Request; Center on Budget and Policy Priorities: Washington, DC, USA, 25 March 2019.

33. National Center for Education Statistics, Institute of Education Sciences. Common Core of Data (CCD) America's Public School. School Characteristics Files (2011-16). Available online: https:/ / nces.ed.gov / ccd/ccddata.asp (accessed on 7 June 2021).

34. National Center for Education Statistics, Institute of Education Sciences. Private School Universe Survey (PSS) (2011-16). Available online: https://nces.ed.gov/surveys/pss/pssdata.asp (accessed on 15 June 2021).

35. Li, H.; Graham, D.J.; Majumdar, A. The effects of congestion charging on road traffic casualties: A causal analysis using difference-in-difference estimation. Acc. Anal. Prev. 2012, 49, 366-377. [CrossRef] [PubMed]

36. Hecht, A.A.; Pollack Porter, K.M.; Turner, L. Impact of the Community Eligibility Provision of the Healthy, Hunger-Free Kids Act on student nutrition, behavior, and academic outcomes: 2011-2019. Am. J. Public Health 2020, 110, 1405-1410. [CrossRef]

37. Cohen, J.F.W.; Hecht, A.A.; McLoughlin, G.M.; Turner, L.; Schwartz, M.B. Universal School Meals and Associations with Student Participation, Attendance, Academic Performance, Diet Quality, Food Security, and Body Mass Index: A Systematic Review. Nutrients 2021, 13, 911. [CrossRef] [PubMed]

38. Moore, Q.; Hulsey, L.; Ponza, M. Factors Associated with School Meal Participation and the Relationship between Different Participation Measures-Final Report; Mathematica Policy Research: Princeton, NJ, USA, 2009; p. 173. Available online: https://eric.ed.gov/ ?id=ED507479 (accessed on 19 June 2021).

39. Gottfried, M.A. Evaluating the relationship between student attendance and achievement in urban elementary and middle schools: An instrumental variables approach. Am. Educ. Res. J. 2010, 47, 434-465. [CrossRef]

40. Allen, C.W.; Diamond-Myrsten, S.; Rollins, L.K. School absenteeism in children and adolescents. Am. Fam. Physician 2018, 98, 738-744. [PubMed]

41. Continuing Appropriations Act, 2021 and Other Extensions Act, P.L. 116-159, Enacted 1 October 2020. Available online: https:/ / www.congress.gov/bill/116th-congress/house-bill/ 8337 (accessed on 19 June 2021).

42. State of Maine Legislature. An Act to Address Student Hunger through Expanding Access to Free School Meals, LD1679. Available online: https:/ /legislature.maine.gov/LawMakerWeb/summary.asp?ID=280080767 (accessed on 26 July 2021).

43. California 2021-22 State Budget. Build Back Boldly. June 28th Package. Available online: https://sbud.senate.ca.gov/sites/sbud. senate.ca.gov/files/June\%2028th\%20Package\%20Summary\%20Final.pdf (accessed on 26 July 2021). 